\title{
The Dynamics of Attracting Switchers: A Cross-Disciplinary Comparison
}

\section{Mr. Corey T Schimpf, Purdue University, West Lafayette}

Corey Schimpf is a PhD student in Engineering Education. His research interests include examining how cyberlearning and informal learning environments can be brought into the engineering curriculum. His dissertation explores how a gaming platform can be used to facilitate early college engineering students design skills development.

\section{Mr. George D Ricco, Purdue University, West Lafayette \\ Dr. Matthew W. Ohland, Purdue University, West Lafayette}

Matthew W. Ohland is Professor of engineering education at Purdue University. He has degrees from Swarthmore College, Rensselaer Polytechnic Institute, and the University of Florida. His research on the longitudinal study of engineering students, team assignment, peer evaluation, and active and collaborative teaching methods has been supported by more than $\$ 12.4$ million from the National Science Foundation and the Sloan Foundation and his team received the William Elgin Wickenden Award for the Best Paper in the Journal of Engineering Education in 2008 and 2011. Ohland is Past Chair of ASEE's Educational Research and Methods division and a member of the Board of Governors of the IEEE Education Society. He was the 2002-2006 President of Tau Beta Pi. 


\title{
The Dynamics of Attracting Switchers: A Cross-Disciplinary Comparison
}

\begin{abstract}
Many retention studies focus on which students enter engineering or how long engineering students persist. We propose studying an alternate pathway, students who switch into engineering from other majors. Examining such pathways reveals a previously understudied aspect of the engineering pipeline and may be leveraged through institutional policies and programs designed for attracting engineering students from other fields.

Survival analysis is a longitudinal statistical method used to analyze the time at which people experience an event, rates of event experience over some measure of time, as well as cases that do not experience an event. Our study implemented discrete survival analysis of a subset of a database comprising more than 1,000,000 unique students. For our current research, we use a sample population of first-time in college (FTIC) students initially matriculating into nonengineering disciplines in two years with population of $\sim 55,000$ at nine institutions. The event of interest is switching into engineering and time is measured in terms enrolled. We compare the results for engineering to two other broad colleges, science, technology and math and social science, to better understand the dynamics and context of attraction into engineering through contrast and comparison.
\end{abstract}

Our preliminary results show that the attraction rates for engineering are lower than both STM and social science. Furthermore, the pool of students who abstain from switching is greatest for engineering, and significantly less for STM and social science. These findings are consistent with other studies using the same database, which gives confidence that the model was constructed properly.

\section{Introduction}

Studies in engineering education such as those that look at retention or success of engineering students or studies that look at student entrance and outreach typically do not focus on late entry into engineering - their focus is on other parts of an engineering student's pathway. One study that did examined late entry ${ }^{1}$ found that engineering has the lowest rates of attraction when compared with other academic fields, but that study did not probe the dynamics of attraction. Thus, the nature of these alternate pathways and the students taking them has not been well documented. To fill this gap, we conducted a survival analysis. Survival analysis is a technique used to examine the time for some population to experience some event (or exit the database). ${ }^{2,3}$ Here we examine attraction rate into engineering by term for students who originally matriculated into a non-engineering field. We likewise ran survival analysis for the potentially analogous comparator of science, technology and math (STM) and potentially divergent comparator social science. Hazard and survival functions are reported for both.

Hazard functions display the term specific hazard or risk of the members of the sample switching into engineering. Survival functions represent the cumulative percentage of those who do not experience the event, taking into account those who are censored or leave the database without experiencing the event. ${ }^{2,3}$ In this study survival functions refer to the population of 
students who do not switch into engineering. Students are censored or removed from the population pool of potentially entering engineering by either leaving the school or graduating. For the two comparators studied here (STM and social science) the same definitions apply, however engineering is replaced with the target school. While the terms 'hazard,' 'risk,' and 'survival' might seem misaligned with the topic studied here, these are the formal methodological terms used in survival analysis. ${ }^{2,3}$ To mitigate this to some degree, we also use the terms attraction and abstention for hazard and survival, respectively. Attraction involves some pull that draws students to switch into a new major. Abstention involves something about a department or field that repels students or keeps them from entering.

Using survival analysis to explore late entry we had two research questions:

1) What is the hazard and survival function of attraction into or abstention from engineering and how does it compare to those for social science and STM?

2) Are there any differences in hazard of entry into engineering by gender and ethnicity/race?

Below, we broadly review how past research problematized late-entry, discuss limitations of these research efforts, and finally discuss research this study builds on. Then the paper turns to how survival analysis was employed. Lastly results for the survival analysis of attraction into engineering and the two comparators, attraction into STM and social science are presented and discussed, in addition to a study of hazard functions for late-entry into engineering by gender and race/ethnicity.

\section{Literature Review}

In the first part of the literature review we briefly cover how other quantitative studies have conceived of the pathways through engineering. We aim to highlight how some pathways through engineering are conceptualized in engineering education.

Research on retention examine factors that increase or decrease student retention rates, e.g. ${ }^{1,4-7}$ Other related research examine the factors the influence students success in engineering, e.g. ${ }^{8,9}$ While studies of this nature identify crucial factors that may explain why students remain or exit engineering, their focus begins after students have entered engineering, thus they do not typically problematize the entry path of students. For instance, while the Chimka, Reed-Rhoads ${ }^{8}$ and Barker proportional hazards model allowed students to exit and return to engineering within the study, this was not the primary focus of the study. Another set of studies focuses on the impetus of outreach programs in drawing students into engineering, e.g. ${ }^{10,11}$ Similar types of studies pay more attention to entry into engineering; however as outreach or entrance studies they tend to focus on entry into the "pipeline," that is upon initial college enrollment, leaving other pathways unexamined. $^{10-12}$

One study of alternate entry points into engineering is Ohland et al, that compares retention and "attraction" rates between engineering and other groups of disciplines such as business, social science, and science, technology, and math. ${ }^{1}$ This study will be reviewed in more detail in a later section of this review. 
Many papers like those discussed above do not consider entry timing into engineering or do so peripherally ${ }^{1,4-7,10-12}$ as they are concerned with other aspects of engineering students or potential students pathways. This leaves them implicitly or explicitly relying on a pipeline model for entry. There are some papers that look at pathways or attraction into different departments within engineering, however. ${ }^{13,14}$

\section{Pipeline Theory and Alternate Conceptions}

Pipeline theory frames students’ pathways through a degree as a pipeline with a "mouth” at college entrance and an "exit" at graduation. People exiting from the pipeline prematurely are considered "leaks" that many studies examine and offer remedies to "block" or "fix". 15,16 Pipeline theory has been criticized heavily for oversimplifying the possible pathways through academic fields. ${ }^{15,17-19}$ A developed understanding of alternative pathways into engineering may lend itself to policies and programs that encourage and support students entering through alternate means.

Taking these students into account shifts our understanding of who comprises engineering students. In her book Feminist Theory: From Margins to the Center, bell hooks ${ }^{20}$ reports on the views and experiences of those in the margins such as minorities and the poor. These groups are, hooks contends, often left out of the "center" of the feminist movement, research and theory. This trend has begun to change in feminism, but hooks use of the margin to re-envision the center remains a useful tool.

Foor, Walden and Trytten's ${ }^{21}$ study provides an excellent example of incorporating historically marginalized groups within engineering. Their study documents the academic career of low SES, multi-ethnic, female student named Inez and her struggles in engineering where she is often cast as an outsider.

Another way that the margins of engineering might reshape our understanding of the center lies in the alternate pathways into engineering such as late-entry, after matriculation. Survival analysis is not well suited to capture the full experience of students like Inez or other marginalized groups, but can be used to analyze alternate pathways like late entry. In so doing, our understanding of who composes the engineering student center shifts us toward a more inclusive and complete image.

\section{Past Survival Analysis in Engineering Education}

Min et $\mathrm{al}^{22}$ and Chimka, Reed-Rhoads and Barker ${ }^{8}$ both use survival analysis to study student retention and graduation respectively. Min et al graphs hazard functions parsed out by gender, ethnicity, SAT Math and Verbal scores, and cohort year to examine rates of risk of exiting ${ }^{22}$.

They conclude that: females are at greater risk to exit early (in semesters 2-4); risk for exit is the greatest for Whites, Minorities, Asians, and other in this order; students with lower SAT Math scores are at greater risk of exit; generally students with lower SAT Verbal are at greater risk of exit; and cohorts exhibit similar risk patterns. Chimka, Reed-Rhoads and Barker ${ }^{8}$ use a proportional hazard model, which does not require graphing hazard functions if the proportionality assumption is upheld, found that for students who submitted SAT scores, those 
with better SAT math scores and females were more likely to graduate in engineering. For those who submitted ACT scores (they were only able to study males due to a violation of the proportional hazards assumption) better science ACT scores raised the odds of graduation as well.

Following Min et $\mathrm{al}^{22}$ and Chimka, Reed-Rhoads and Barker ${ }^{8}$, we also explore the hazard functions of entry by gender and ethnicity. Ohland et al $^{1}$ found that there were significant differences in attraction rates across broad academic fields. Engineering displayed the lowest levels of attraction, $7 \%$, whereas other fields show rates between 35\%-60\%, with STM at $41 \%$ and social science at $60 \% .{ }^{1}$ Thus in order to get a more complete understanding of attraction behavior we compare engineering hazard functions with an analogous comparator (science, technology and math students) and a divergent comparator (social science students).

Attraction involves some drawing force or attributes. ${ }^{23}$ Aspects of a department or field "pull” students into the field_-aspects like those identified by Walden and Foor $^{14}$ —including formal and informal recruiting, supportive community, and feeling of fit or identification. We also use the concept of abstention, which is more difficult to identify, and occurs where something about a department or field keeps students from entering it.

Having laid the foundation for this study, the paper now turns to a discussion of how we employed survival analysis.

\section{Methods}

Data for this study came from the Multiple-Institution Database for Investigating Engineering Longitudinal Development (MIDFIELD) that contains transcript-like records for 12 institutions starting in 1988 and continuing to the present, each year adding more data. Most recently data from 2011 were added to the database for some institutions. All of the schools in the database have engineering programs, but data are collected for all undergraduate degree-seeking students. We selected a subset of this much larger database, the cohort years of 1993 and 1997. We selected two cohort years so the risk of a group of students entering at the same time could be tracked along their undergraduate degree tenure. As Min et $\mathrm{al}^{22}$ found minimal differences among cohort groups, these two cohorts are collapsed and studied as one.

We employed a discrete time survival analysis ${ }^{2}$. We measured time in semesters and displayed many of our results for 12 semesters (fall and spring semesters) or 6 years into the degrees, a common length of time for studying retention related topics in engineering education. We created a separate database for each major: engineering; social science; and STM. While the full list is extensive, the fields that fall under social science include: many education fields, language fields, area studies (including race, ethnicity, gender), archeology, anthropology, demography, geography, political science, sociology, social science and urban studies (full list provided on request). For each database we used the same initial sample of the two cohort years. We eliminated students who matriculated into the major of interest since they had already "experienced" the event and could not be attracted into their current field. Due to complications of causing the risk set to grow as time advanced and the preliminary nature of this study, any transfer students or students with transfer hours were dropped from the study. Thus the 
population for each study started at matriculation (but was explicitly outside the field of interest) and preceded in discrete time steps semester by semester, eventually experiencing the event (major-switching, attraction into a field) or being censored (graduation, leaving the school).

\section{Results}

First we begin with lifetables for each major of interest to sketch a basic description of the three student sub-samples, how likely the events are in these sub-samples, and where censoring is happening. In the lifetable, the risk set column is the total number of students who could experience the event in a given term, the attraction events are the number of students who actually switch, censored on the number who leave school or graduate, and hazard and survival are as defined earlier.

\begin{tabular}{|c|c|c|c|c|c|}
\hline \multicolumn{6}{|c|}{ Table 1 Engineering Lifetable } \\
\hline $\begin{array}{l}\text { Interval } \\
\text { (Semester) }\end{array}$ & Risk Set & $\begin{array}{c}\text { Attraction } \\
\text { Events }\end{array}$ & Censored & Hazard & Survival \\
\hline 1 & 49877 & 0 & 434 & 0 & 1 \\
\hline 2 & 49453 & 314 & 4209 & .0063 & .9937 \\
\hline 3 & 44930 & 327 & 2205 & .0073 & .9864 \\
\hline 4 & 42398 & 354 & 2505 & .0083 & .9783 \\
\hline 5 & 39542 & 264 & 1546 & .0067 & .9717 \\
\hline 6 & 37732 & 120 & 1621 & .0032 & .9686 \\
\hline 7 & 35991 & 82 & 2291 & .0023 & .9664 \\
\hline 8 & 33618 & 40 & 7047 & .0012 & .9653 \\
\hline 9 & 26531 & 32 & 6937 & .0012 & .9641 \\
\hline 10 & 19562 & 14 & 6910 & .0007 & .9634 \\
\hline 11 & 12638 & 21 & 4843 & .0017 & .9618 \\
\hline 12 & 7774 & 10 & 3093 & .0013 & .9606 \\
\hline
\end{tabular}

Looking at Table 1 for "attraction” into engineering contrasted with the total population (risk set) who could be "attracted", it becomes clear that switching into engineering is a rare event (as it is for other discipline groups). No events happen in interval one as all students matriculating into engineering were dropped from this particular sub-sample, which was repeated in the other subsamples. Censoring starts early and this is primarily due to students leaving the university. The spike in exit around semesters 8-9 correspond to the end the typical four year degree, so 
while there is heavy censoring by this time, it is expected as many students are graduating. The lifetables in this section only display intervals through semester 12 or the end of year six as mentioned above. Although there are some students who remain beyond this point, event occurrence becomes vanishingly small, as is the risk set as $90.6 \%$ of the students have exited by the end of term 12 (either through graduation or departure). Exact numbers of censored students and when students experience "attraction" varies by lifetable, however the general points above hold for all three sub-samples examined.

Turning to the engineering sub-sample specifically we see that the risk set starts at 49,887. Event occurrence by term is minimal. The highest is 354 in term 4. Generally the highest counts of event experience and highest hazards for those attracted into engineering happen between semesters 2-5. By the end of the lifetable, only 4\% experienced the event and $96 \%$ have "survived." Note that this percentage is based on the set of students who could possibly switch into engineering (the source population), whereas the $7 \%$ reported by Ohland et al ${ }^{1}$ is based on the set of students enrolled in engineering in Semester 8 (the target population).

\begin{tabular}{|c|c|c|c|c|c|}
\hline \multicolumn{6}{|c|}{ Table 2 Social Science Lifetable } \\
\hline $\begin{array}{c}\text { Interval } \\
\text { (Semester) }\end{array}$ & Risk Set & $\begin{array}{l}\text { Attraction } \\
\text { Events }\end{array}$ & Censored & Hazard & Survival \\
\hline 1 & 57149 & 0 & 428 & 0 & 1 \\
\hline 2 & 56721 & 908 & 4544 & .0160 & .9840 \\
\hline 3 & 51359 & 1056 & 2434 & .0206 & .9638 \\
\hline 4 & 47869 & 1401 & 2586 & .0293 & .9356 \\
\hline 5 & 42882 & 948 & 1566 & .0216 & .9153 \\
\hline 6 & 41368 & 684 & 1594 & .0165 & .9002 \\
\hline 7 & 39090 & 559 & 2239 & .0143 & .8873 \\
\hline 8 & 36392 & 403 & 7280 & .0111 & .8775 \\
\hline 9 & 28709 & 258 & 6872 & .0090 & .8696 \\
\hline 10 & 21579 & 177 & 6818 & .0082 & .8625 \\
\hline 11 & 14584 & 113 & 4787 & .0077 & .8558 \\
\hline 12 & 9684 & 70 & 3440 & .0072 & .8496 \\
\hline
\end{tabular}


Considering the social science lifetable (table 2) it can be seen that the sub-sample was larger than engineering, starting at 57,149. Event occurrence is still minimal compared to the full subsample population, but is higher than engineering. Absolute numbers of who experienced the event as well as hazards are the highest in semesters 2-5, again. By the end of the lifetable 15\% experienced the event or $85 \%$ "survived" or abstained from social science. The STM lifetable

\begin{tabular}{|l|l|l|l|l|l|}
\hline \multicolumn{7}{|c|}{ Table 3 STM Lifetable } \\
\hline $\begin{array}{c}\text { Interval } \\
\text { (Semester) }\end{array}$ & \multicolumn{1}{|c|}{ Risk Set } & $\begin{array}{c}\text { Attraction } \\
\text { Events }\end{array}$ & \multicolumn{1}{|c|}{ Censored } & Hazard & Survival \\
\hline 1 & 51970 & 0 & 409 & 0 & 1 \\
\hline 2 & 51561 & 1444 & 4076 & .0280 & .9720 \\
\hline 3 & 46041 & 1563 & 2269 & .0339 & .9390 \\
\hline 4 & 42209 & 1452 & 2489 & .0344 & .9067 \\
\hline 5 & 38268 & 1021 & 1681 & .0267 & .8825 \\
\hline 6 & 35566 & 694 & 1826 & .0195 & .8653 \\
\hline 7 & 33046 & 478 & 2215 & .0143 & .8529 \\
\hline 8 & 30357 & 318 & 6197 & .0105 & .8439 \\
\hline 9 & 23842 & 248 & 5920 & .0104 & .8352 \\
\hline 10 & 17674 & 142 & 5631 & .0080 & .8285 \\
\hline 11 & 11091 & 86 & 3972 & .0072 & .8225 \\
\hline 12 & 7843 & 58 & 2824 & .0074 & .8164 \\
\hline
\end{tabular}

(table 3) starts with a sub-sample population of 51,970. In hazard rate and absolute numbers the greatest risk for "attraction" is in semesters 2-5, with a peak in semester 4. By the end of the periods examined, $82 \%$ abstained from switching into STM or $18.36 \%$ were attracted into the field. These results are now displayed in the hazard and survivor functions graphed below. 


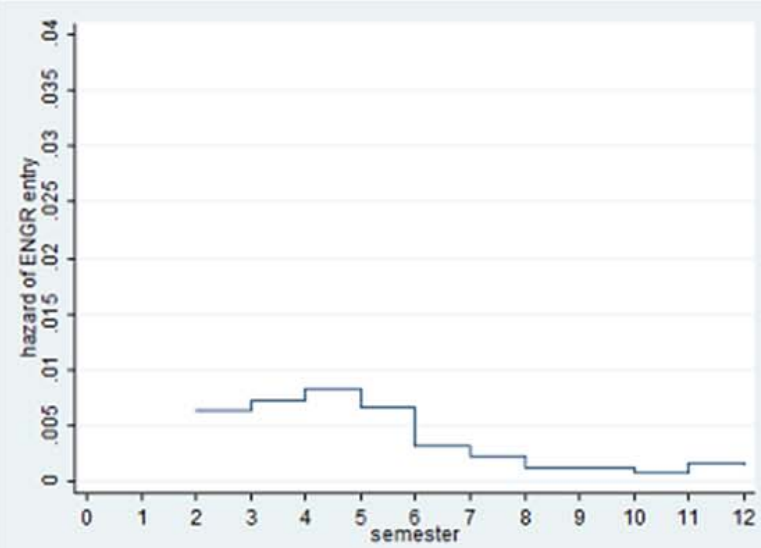

(a)

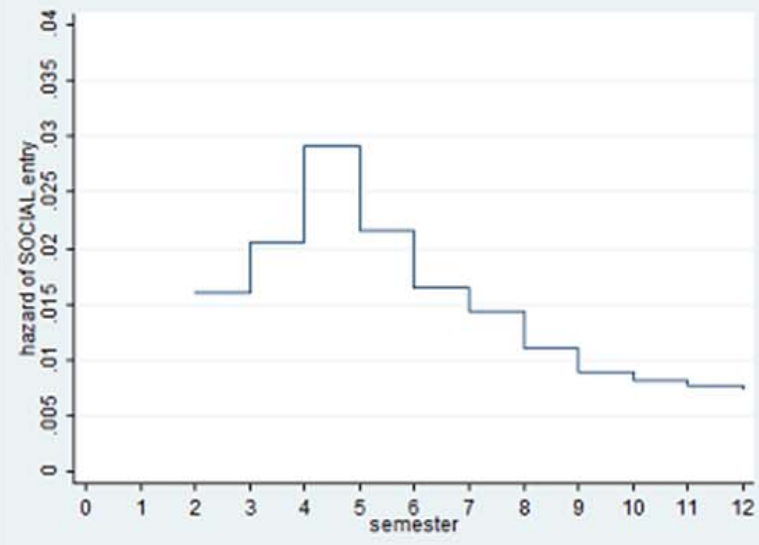

(c)

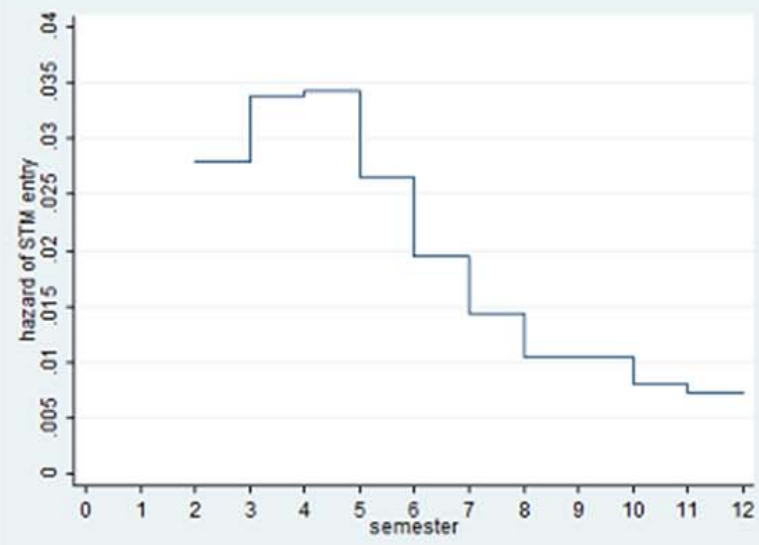

(e)

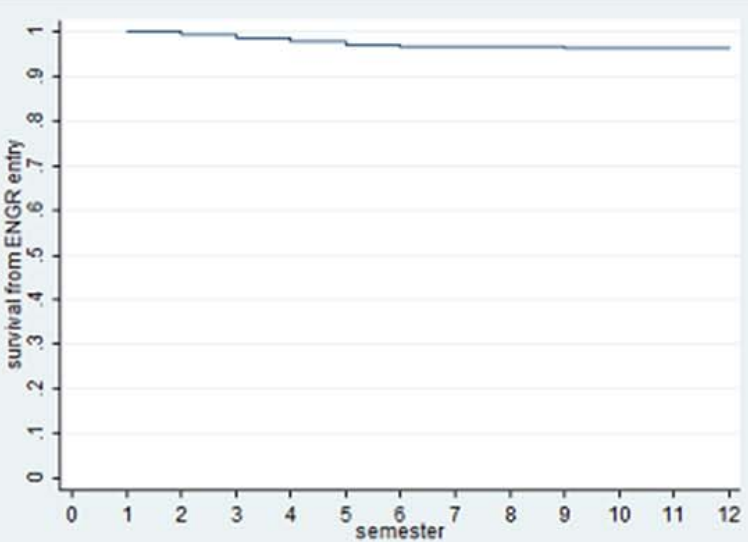

(b)

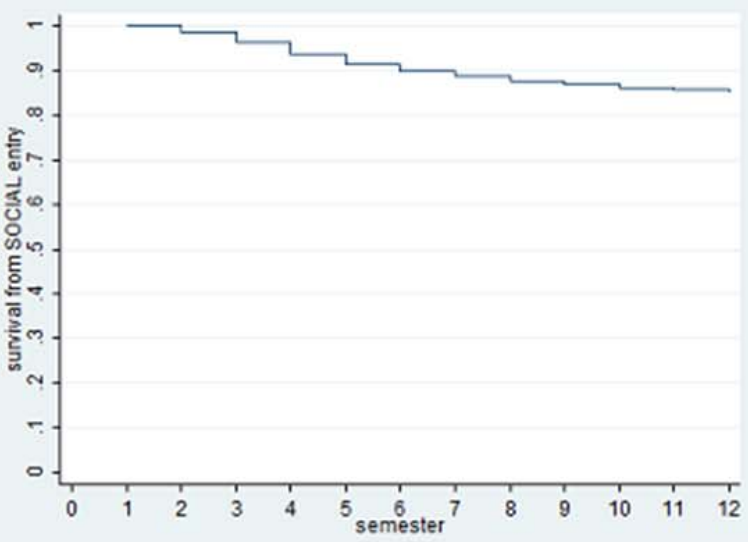

(d)

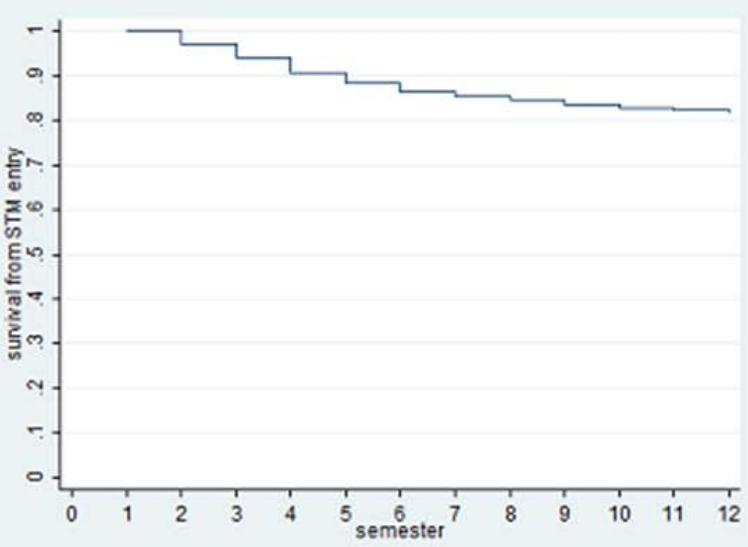

(f)

Figure 1 - Hazard (left) and Survival (right) rates by semester for the three sub-sample populations.

Figure 1 shows the hazard (a) and survival (b) function for engineering. The hazard rate peaks at $.83 \%$ in semester 4 , not quite reaching one percent hazard. Hazard in semesters 2-5 stay near this level but after semester 5 hazard tapers off and approaches 0 . The survival function, which shows the cumulative level of people not experiencing the event has the biggest drops in the early 
semesters identified above and settles around $96 \%$ survival rate by the end of semester 12 . Graphs (c) and (d) display the hazard and survival function for social science attraction. Again hazard is the highest in semester 4-2.92\%. Hazard remains high between semesters 2-5 and then tapers off as was the case for engineering. The survival function shows a similar pattern, dropping more in the early semesters and then slowing down, eventually stopping at $85 \%$ by the end of semester 12. Finally $(\boldsymbol{e})$ and $(\boldsymbol{f})$ display the hazard and survival function for STM. Hazard is the highest in semester four at 3.44\%, highest of all 3 majors, and is generally high between semesters 2-5. After this, hazard rates taper off. A similar pattern is seen in the survivor function, dropping more in the early semesters and then taping off and landing at $82 \%$ at the end of semester 12. It is important to caution that while there is overlap between the sub-sample populations there are also differences which constrain the comparisons between fields.

Finally we look at the hazard functions of students attracted to engineering disaggregated by gender and ethnicity to better understand what groups of students travel through alternate entry pathways. We report hazard functions for males and females are reported as well as Whites, Blacks and Asians. Due to either small numbers in these two cohorts (Native Americans and international students) or very limited event occurrence (Hispanics and students in the 'other' category) we only report on Asians, Blacks and Whites in this preliminary work.

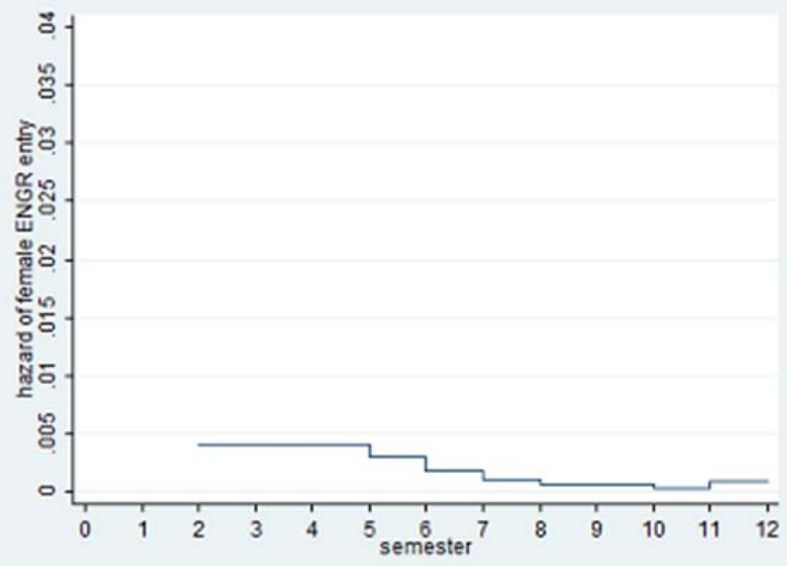

(a)

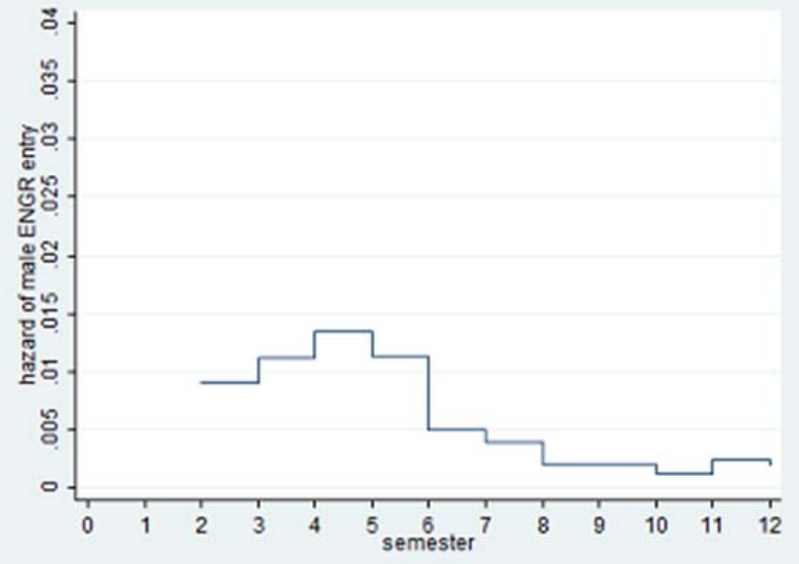

(b)

Figure 2 - Hazard rates by semester for females (a) and males (b) late-entry into engineering.

Comparing the hazard functions for females (b) and males (a) in Figure 2 it becomes clear that while the hazard peaks for both groups around semester four, the hazard rate of males, .0155, is much higher than that of females, which peaks at .0045. Again, hazard is generally high between semesters 2-5, and females' hazard function is flatter at the start, whereas males have a more distinct peak. Turning to whites (a) and asians (b) in Figure 3, both have peaks higher than the pooled hazard above (.83) with .88 and .0289 respectively. As a subpopulation switching into engineering, asians peak hazard rate is closer to the pooled hazard of students who were attracted to the social sciences or STM. Both whites and Asians have a similar shape with raised hazard rates in semesters 2-5 (2-6 for whites) which is followed by a steep drop in hazard. Blacks (c), on the other hand, have markedly lower rates of hazard, which peaks in semester 1 at .0058 and drops consistently, with the exception of semester 3 and 4, as time progresses. Lastly, note that while males and females exist in similar portions in the dataset, there are larger differences between different racial/ethnic groups. 


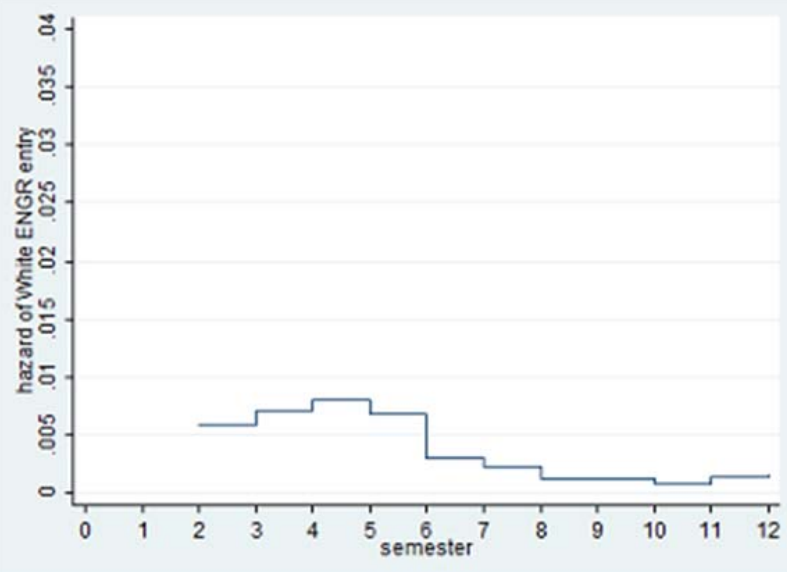

(a)

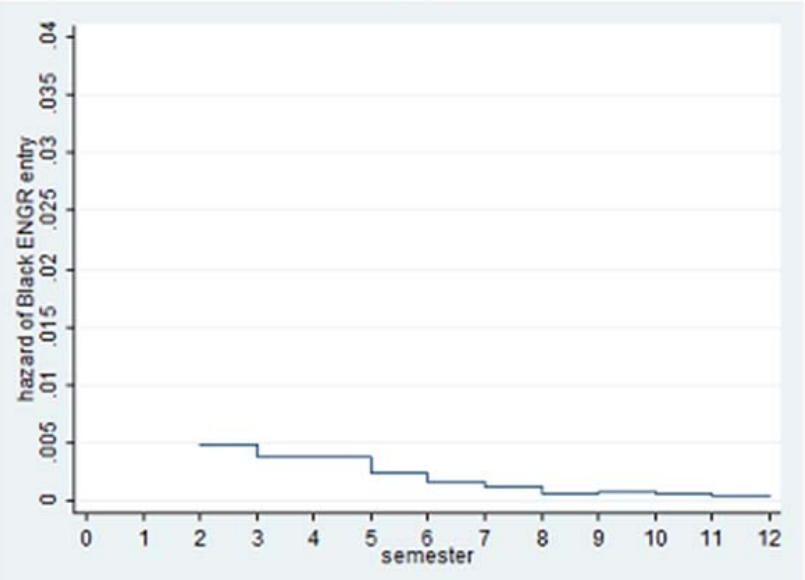

(c)

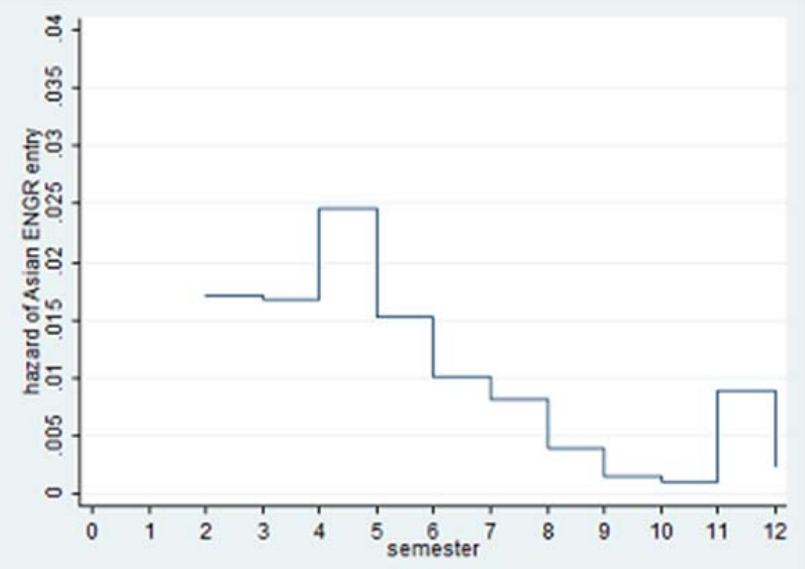

(b)

Figure 3 - Hazard rates by semester for Whites (a), Asians (b) and Blacks (c) late-entry into engineering.

\section{Discussion}

Comparing hazard functions, engineering has the lowest attraction rates, with a $0.83 \%$ peak compared to 3.44\% for STM and 2.92\% for social sciences and conversely the highest survival rate at $96 \%$ of the sub-samples pool abstaining compared to $85 \%$ for social sciences and $81 \%$ for STM. This is particularly significant for engineering in light of the similarities across fields in the timing of attraction events. If many students are attracted to other departments around the same time in their academic careers, clearly those departments with higher attraction rates will benefit more. While it is difficult to prove non-action (i.e. why students were not attracted to engineering) the combination of comparatively low attraction levels (also corroborated by Ohland et $\mathrm{al}^{1}$ ) high survival from the pool of potential candidates and the chronic difficulties engineering has faced as a field, such as young people being unfamiliar with engineering or what engineers $\mathrm{do}^{24}$, the rigid curricular structure ${ }^{25}$ and other factors such as engineering academic culture (e.g. ${ }^{26}$ ) suggest that abstention may be operating. The possibility of and concern about abstention as a process is further highlighted by the results of the hazard functions broken down by gender and race/ethnicity. Males, Asians and Whites, populations that are well represented in engineering had higher hazard rates or attraction into engineering than females and Blacks; 
populations that are underrepresented in engineering ${ }^{27}$. Thus although survival analysis allowed us to examine alternate pathways into engineering this "marginal" pathway at least for the cohorts observed here, is not helping to redefine the center, but rather is a reflection of the populations already considered to comprise the center of the engineering student body. Including other racial, ethnic and national identities that could not be included here might reveal different insights into what students traverse these pathways.

\section{Conclusion}

Limitations to this study include: most importantly, the focus of students' first entry into a new field after a previous matriculation; inability to graph the hazard functions of some groups due to data issues; SAT Math and SAT Verbal, previously found to be influential for engineering success $^{12,22}$, not viable due to data collection methods; only two cohorts were studied; and the lack of transfer students inclusion. Concerning the delimitation of the first entry after matriculation, some pathways may be more complex than those studied here and there is no guarantee that those who switch into engineering or any other field will remain.

In this data-set, once the transfer students were dropped there were approximately 12,000 students entering as engineers out of a total sample size of approximately 61,000. Observing late entry students, approximately 1,600 switched into engineering after starting in some other field, or about 13 percent of the initial sample — not nearly as large as those who matriculated in, but also not an insignificant number for these alternate pathways. Furthermore, there is a similar pattern when students are attracted to new majors; students seeking a new field could increase the number of students in engineering if attraction rates were higher (or abstention lower). Examining alternate pathways such as the ones explored here can lead to a better understanding of how students enter and exit engineering, which can permit a more comprehensive view of the engineering student body, who composes it, how to attract and retain such students and how we might engender a more diverse student body.

\section{Acknowledgements}

This work is supported by the National Science Foundation (NSF) through awards 0811194 and 0935157. The opinions expressed in this article are those of the authors and do not necessarily reflect the views of the NSF.

\section{References}

1 Ohland, M.W., Sheppard, S., Lichtenstein, G., Eris, O., Chachra, D. \& Layton, R.A., "Persistence, Engagement, and Migration in Engineering Programs,” Journal of Engineering Education, vol 97, 2008.

2 Singer, J. D., \& Willett, J. B. Applied Longitudinal Data Analysis: Modeling Change and Event Occurrence, First edition. NY, New York: Oxford University Press, 2003.

3 Singer, J. D., \& Willett, J. B. "Modeling the Days of our Lives: Using Survival Analysis When Designing and Analyzing Longitudinal Studies of Duration and the Timing of Events," Psychological Bulletin, vol. 110, pp. 268-290, 1991.

4 Li, Q., Swaminathan, H. \& Tang, J., “Development of a Classification System for Engineering Students Characteristics Affecting College Enrollment and Retention,” Journal of Engineering Education, vol. 98, pp. 
361-376, 2009.

5 Marra, R.M., Rodgers, K.A., Shen D. \& Bogue B., "Women Engineering Students and Self-Efficacy: Multi-Year, Multi-Institution Study of Women Engineering Student Self-Efficacy,”Journal of Engineering Education, vol. 98, pp. 27-38, 2009.

6 Hartman, M., \& Hartman, M. "Leaving Engineering: Lessons from Rowan University? s College of Engineering'” Journal of Engineering Education, vol. 95, pp. 49-61, 2006.

7 Bestfield-Sacre, M., Moreno, M., Shuman, L.J. \& Atman, C.J., "Gender and Ethnicity Differences in Freshman Engineering Student Attitudes: A Cross Institutional Study,” Journal of Engineering Education, vol. 90, pp. 477-489, 2001.

8 Chimka, J. R., Reed-Rhoads, T., \& Barker, K. "Proportional hazards models of graduation," Journal of College Student Retention: Research, Theory and Practice, vol. 9, pp. 221-232, 2008.

9 Zhang, G., Anderson, T. J., Ohland, M. W., \& Thorndyke, B. R. "Identifying factors influencing engineering student graduation: A longitudinal and cross-institutional study," Journal of Engineering Education, vol. 93, pp. 313-320, 2004.

10 Fantz, T. D., Siller, T. J., \& DeMiranda, M. A. "Pre-Collegiate Factors Influencing the Self-Efficacy of Engineering Students," Journal of Engineering Education, vol. 100, pp. 604-623, 2011.

11 Nadelson, L. S., \& Callahan, J. M. "A comparison of two engineering outreach programs for adolescents," Journal of STEM Education: Innovation and Outreach, vol. 12, pp. 43-54, 2011.

12 Nicholls, G.M., Wolfe, H., Besterfield-Sacre, M. Shuman, L.J. \& Larpkiattaworn, S. “A Method for Identifying Variables for Predicting STEM Enrollment,” Journal of Engineering Education, vol. 96 pp. 33-44, 2007.

13 Ricco, G. et al., "Describing the Pathways of Students Continuing and Leaving Engineering," presented at American Society for Engineering Education Annual Conference, Louisville, Kentucky, 2010.

14 Walden, S. E., \& Foor, C. “ 'What's to keep you from dropping out?' Student Immigration into and within Engineering," Journal of Engineering Education, vol 97, pp. 191-205, 2008.

15 Metcalf, H. "Stuck in the pipeline: A critical review of stem workforce literature," InterActions: UCLA Journal of Education and Information Studies, vol. 6, 2010.

16 Berryman, S.E., "Who Will Do Science? Trends and Their Causes in Minority and Female Representation among Holders of Advanced Degrees in Science and Mathematics," NY: New York: Rockefeller Foundation, 1983.

17 Pawley, A.L. \& Hoegh, J. “Exploding Pipelines: Mythological Metaphors Structuring Diversity-Oriented Engineering Education Research Agendas.” presented at American Society for Engineering Education Annual Conference, Vancouver, British Columbia, 2011.

18 Xie, Y. and Shauman K.A., "Women in science: Career processes and outcomes," Cambridge, MA: Harvard University Press, 2003.

19 Allen, M. \& Castleman, T., "Fighting the pipeline fallacy, in Gender and the restructured university: Changing management and culture in higher education," Ann Brooks and Alison MacKinnon, Editors., Philadelphia, PA: Open University Press, 2001.

20 hooks, b. Feminist Theory: From Margin to Center, Second edition. Cambridge, MA: South End Press, 2000.

21 Foor, C. E., Walden, S. E., \& Trytten, D. A. " ' I Wish that I Belonged More in this Whole Engineering Group:'Achieving Individual Diversity," Journal of Engineering Education, vol. 96, pp. 103-115, 2007.

22 Min, Y., Zhang, G., Long, R.A., Anderson, T.J. \& Ohland, M.W., "Nonparametric Survival Analysis of the Loss Rate of Undergraduate Engineering Students," Journal of Engineering Education, vol 100, pp. 349-373, 2011. 
23 Hartman, H., \& Hartman, M. "Do Gender Differences in Undergraduate Engineering Orientations Persist when Major is Controlled?" International Journal of Gender, Science and Technology, vol. 1, 2009.

24 National Academy of Engineering: Committee on Public Understanding of Engineering Messages, “Changing the Conversation: Methods for Improving Public Understanding of Engineering." Washington, D.C., National Academies Press.

25 Sheppard, S., Macatangay, K., Colby, A. \& Sullivan, W.M., “Educating Engineers: Designing for the Future of the Field, CA: San Francisco: Josey-Bass, 2008.

26 Tonso, K. L., “Teams that work: Campus culture, engineer identity, and social interactions,” Journal of Engineering Education, vol. 95, 2006.

27 National Science Foundation, "Women, Minorities, and Persons with Disabilities in Science and Engineering: 2011. Special Report NSF 11-309," National Science Foundation, Division of Science Resources Statistics, Arlington, VA2011. 